\title{
Gas Hydrates Accumulations on the South Shetland Continental Margin: New Detection Possibilities
}

\author{
V. D. Solovyov, ${ }^{1}$ V. G. Bakhmutov, ${ }^{2}$ I. N. Korchagin, ${ }^{3}$ S. P. Levashov, ${ }^{4}$ \\ N. A. Yakymchuk, ${ }^{4}$ and D. N. Bozhezha ${ }^{4}$ \\ ${ }^{1}$ Department of Seismometry and Physical Properties of the Earth, Institute of Geophysics of National Academy of Science of Ukraine, \\ Palladin Avenue 32, 03680 Kyiv, Ukraine \\ ${ }^{2}$ Department of Geomagnetism, Institute of Geophysics of National Academy of Science of Ukraine, \\ Palladin Avenue 32, 03680 Kyiv, Ukraine \\ ${ }^{3}$ Department of Geothermy and Modern Geodynamics, Institute of Geophysics of National Academy of Science of Ukraine, \\ Palladin Avenue 32, 03680 Kyiv, Ukraine \\ ${ }^{4}$ Institute of the Applied Problems of Ecology, Geophysics and Geochemistry, Laborator Street 1, 03133 Kyiv, Ukraine
}

Correspondence should be addressed to V. D. Solovyov, valera@igph.kiev.ua

Received 19 April 2011; Revised 26 July 2011; Accepted 27 July 2011

Academic Editor: Umberta Tinivella

Copyright (C) 2011 V. D. Solovyov et al. This is an open access article distributed under the Creative Commons Attribution License, which permits unrestricted use, distribution, and reproduction in any medium, provided the original work is properly cited.

\begin{abstract}
The results of investigations in 2006-2010 for hydrocarbon and gas hydrates on the Antarctic Peninsula continental margin are given. In 2004 and 2006, the marine geoelectric researches by methods of forming a short-pulsed electromagnetic field (FSPEF) and vertical electric-resonance sounding (VERS) had been conducted in this region. The "deposit" type anomaly was mapped by FSPEF survey, and anomalous polarized layers of "hydrocarbon deposit" type were chosen by VERS sounding within this anomaly on Antarctic margin in the region of UAS "Academician Vernadsky." Anomalous zones of "gas hydrate deposit" type were detected on the South Shetland margin due to the special technology of satellite data processing and interpretation using. These results confirm the high gas hydrates potential of the West Antarctica region. Some practical results of the experimental approbation of these original technologies for the "direct" prospecting and exploration of hydrocarbon (HC) and gas hydrates accumulations in different oil-and-gas bearing basins of Russia and Gulf of Mexico are proposed. The integration of satellite data processing and materials of FSPEF-VERS methods enable improving their efficiency for different geological and geophysical problems solving.
\end{abstract}

\section{Introduction}

Previous studies have revealed the real possibilities of new mobile geophysical technologies using for hydrocarbon (HC) accumulations prospecting [1-6]. One of this technologies, method of forming a short-pulsed electromagnetic field (FSPEF) and vertical electric-resonance sounding (VERS), makes possible the efficient and accurate determination of a stratigraphic (geologic) model beneath a sounding site. The first publications about this technology as a whole had appeared in Russian (in 2001), in English-in 2003 $[1,2]$. The basic physical principles that underlie the method of VERS probing described in English in the patent nos. 7227362,7248052 (USA, 2007). On the basis of this patent in the United States was elaborated the power imaging (PI) geophysical prospecting method to aid in the exploration for hydrocarbons. PI technology is used to confirm the thickness and depth of expected hydrocarbon zones and provides a means for the direct detection of hydrocarbons [7].

Express technology of "direct" prospecting of the HC accumulations by geoelectric methods (FSPEF-VERS) was developed by experiments on the known oil and gas fields within the largest gas and condensate fields of Ukraine and once again showed the working capacity and economic efficiency of the FSPEF-VERS technology [1-6]. The geoelectric researches on some oil and gas fields allow finding out new perspective sites and horizons and may be used for operative prospects estimation of the deep productive horizons. The FSPEF-VERS technology has passed approbation on more than 55 known oil and gas fields. The "deposit" type 
anomalies were fixed by the FSPEF survey on all oil and gas fields. The anomalous polarized layers (APL) of "oil" and "gas" type were chosen by VERS soundings in cross-section within the mapped anomalies. The "deposit" type anomalies were mapped also by FSPEF method within 70 perspective structures and separate areas from the 97 examined.

The second used technology for mobile HC accumulation prospecting is based on the satellite special data processing and interpretation and on the selection and processing of the resonance frequencies of the electromagnetic field data for each type of hydrocarbons' compounds. New (nonclassical) methods of geophysical research focused on direct search for specific physical substances with a characteristic set of properties: oil, gas, gas hydrates, water, various minerals, and rocks. The first method of satellite data interpretation is connected with electromagnetic fields structure of definite substance studying $[8,9]$.

"Spatial-frequency electromagnetic fields structure of any substance is determined by the chemical composition and spatial structure of molecules or the crystal lattice of the substance. A large number of homogeneous matters will create a collective characteristic of the substance in the electromagnetic field radiation power which is proportional to the substance concentration in a given direction. We can assume that the linear-polarized wave with a given frequency response carries information about the structure of the substance and is not absorbed by the medium, and the wave intensity does not decrease with distance. The homogeneous substance at any depth would create a field as if the substance was on the surface. It turned out that the characteristic electromagnetic wave of a large quantity of oil and gas is fixed in a certain way in satellite images. In most cases the technology of the quantum-optical satellite imagery filtration allows to identify the boundaries of oil and gas projected fields anywhere in the world and to record the density of stocks distribution" [5]. There are also the method of the distance-controlled discovery of HC deposits [6] and InfoScan technology, which is based on processing of analog photo material [9]. Accuracy of object location detecting directly depends on the scale of the investigated photograph.

This original satellite data processing technology may be integrated also with the traditionally used methods of HC accumulations and gas hydrates prospecting as well as with nonclassical geophysical technologies.

\section{Some Results of Proposed Technologies Practical Using}

The first successful approbation of this technology was conducted on the known hydrocarbon fields and gas hydrates occurrences.

\subsection{Continental Margin of Antarctica. First approbation of} these special methods was realized for the area situated not far from the Ukrainian Antarctic station (UAS) "Academic Vernadsky" (Figure 1).

The HC-potential experience has shown that oil and gas deposits may be associated with large zones of tectonic

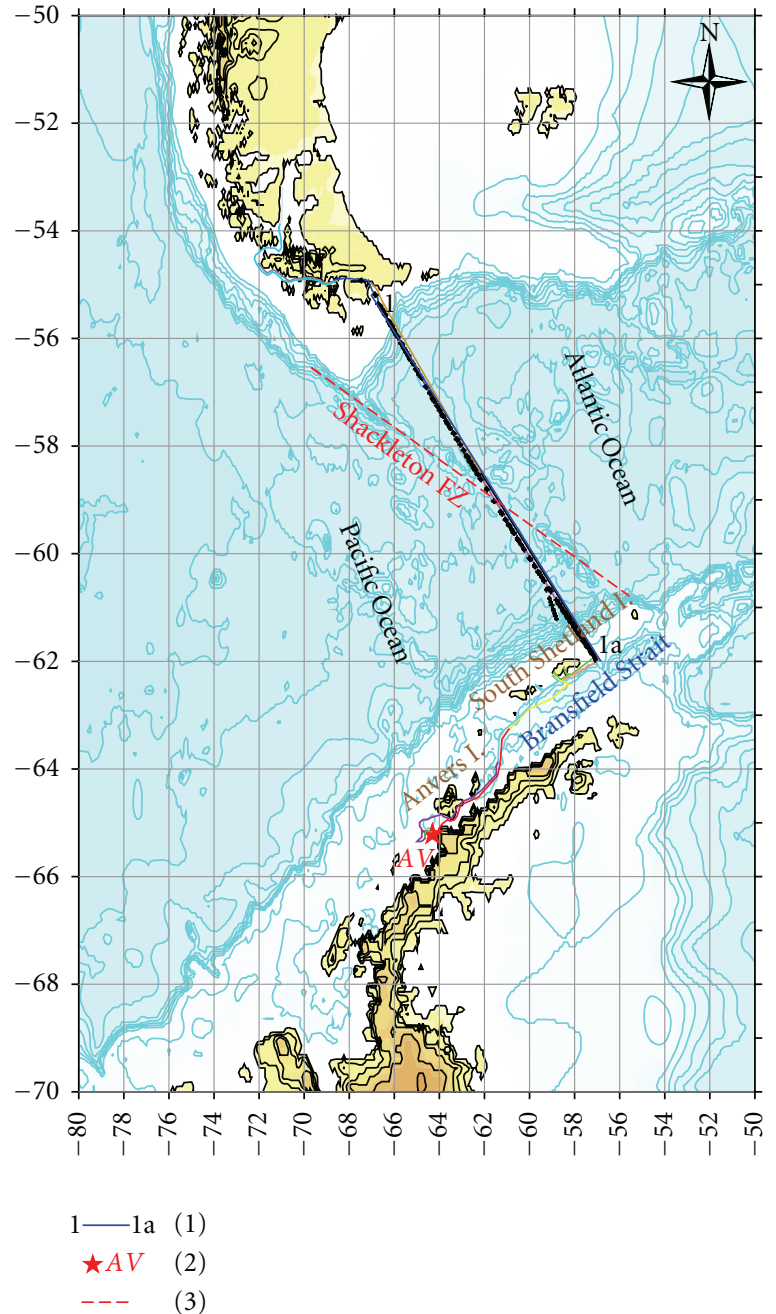

FIGURE 1: The scheme of the ship motion and location of the FSPEF-VERS-profiles in 11th UAE (2006). Legend: (1) sounding profile through Drake Passage; (2) UAS "Academician Vernadsky" (Galindez Island); (3) Shackleton fracture zone.

fractures and rift structures of the continental margin of Antarctica. There are necessary conditions to generate and for the inorganic synthesis of $\mathrm{HC}$ of different types. The HC formation may be connected with the presence of subglacial drainage network which helps the crustal fluids and gases to move in Antarctic continental shelf direction.

Marine researches with FSPEF-VERS technology were fulfilled during the seasonal works of the Ukrainian Antarctic expeditions (UAE) with the aim of studying the crustal structure of Drake Passage and Bransfield Strait down to depth of $>30 \mathrm{~km} \mathrm{[4].} \mathrm{This} \mathrm{method} \mathrm{was} \mathrm{also} \mathrm{used} \mathrm{for} \mathrm{the}$ hydrocarbon accumulations prospecting on the Antarctic Peninsula continental margin near Anvers Island. One "deposit" type anomaly (DTA) zone was mapped by VERS sounding in depth interval up to $3500 \mathrm{~m}$ (Figure 2).

We applied the special method of satellite data processing and used only reconnaissance character which was carried out on the investigated sites (Figure 3). 

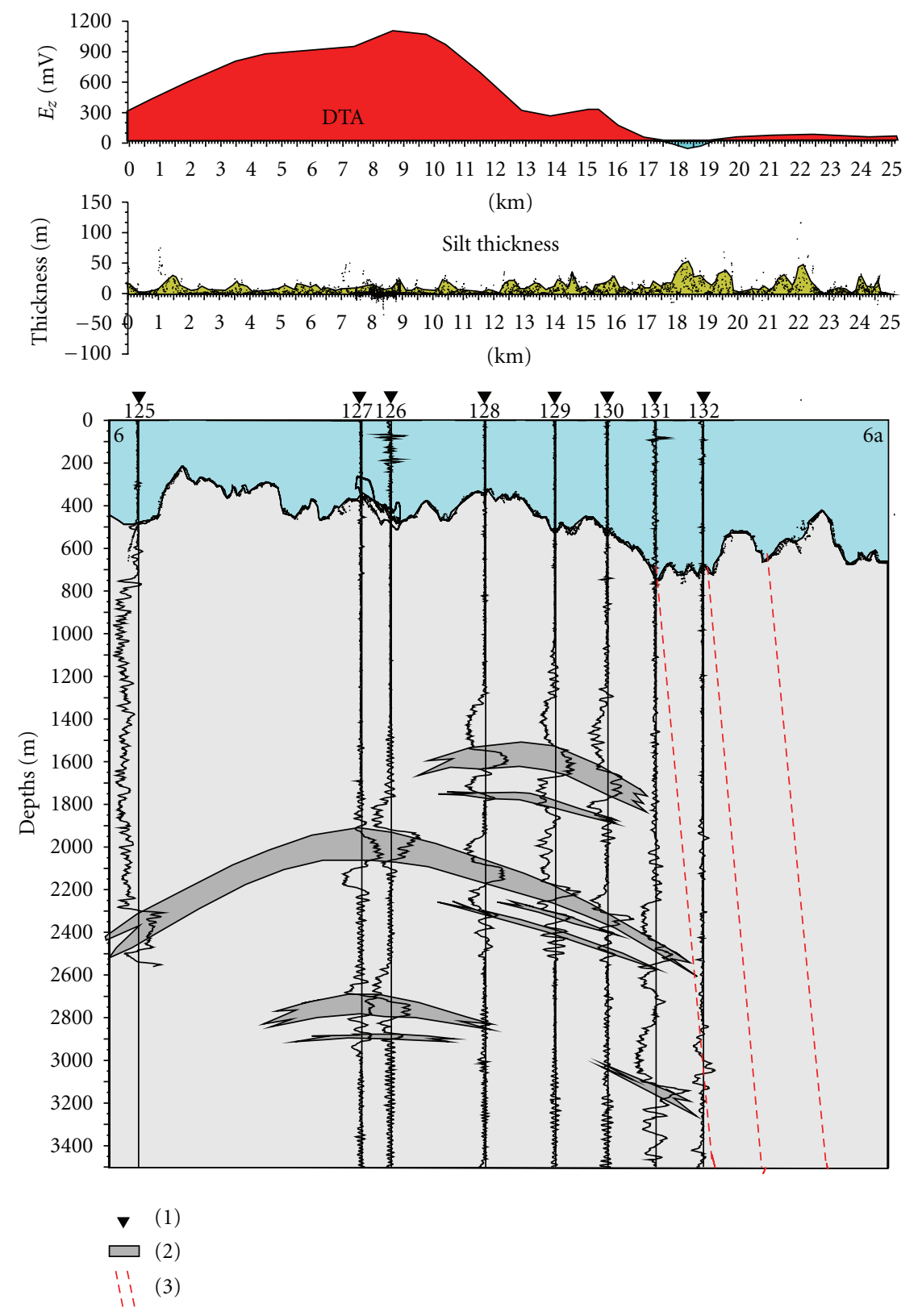

FIgURE 2: The VERS sounding data over geoelectric anomalous zone of the "hydrocarbon deposit" type in the Antarctic Peninsular region. (1) Sounding points (125-132); (2) anomalous polarized layers of "hydrocarbon deposit" type; (3) tectonic fracture zone.

It means that a number of small and possibly mediumsized objects (fields) could be omitted. However, during the larger-scale data processing they can be identified and mapped. The points of anomalous response values determination are shown on figure. The accuracy and detail of the anomalous objects mapping can be increased substantially when the concentration of points will be raised.

\subsection{Experiments on Gas Hydrate and Oil Fields. Traditional} energy sources deficiency arouses scientific and practical interest to nontraditional sources and the gas hydrates deposits. Gas hydrates are solid compounds of the gas molecules and water that exist under certain values of pressure and temperature.
The Messoyakh field in Russia was the first deposit with gas hydrate concentrations. It is located in the north-eastern part of Western Siberia and was discovered in 1967 [10, 11].

The deposits of natural gas and gas hydrates are installed there in dome trap of Cenomanian productive stratum (Dolgan formation) at $800-900 \mathrm{~m}$ depth. There are several hypotheses of Dolgan deposits structure. By one of them the gas hydrate deposits are located in the structure roof, and the gas reservoir is underlain by water at the structure base [10].

The satellite data processing for the Messoyakh gas hydrates deposits area (Figure 4) was carried out to verify the correctness of these parameters determined in order to find the anomalous zones of "gas hydrates deposit" type in the Antarctic region. 


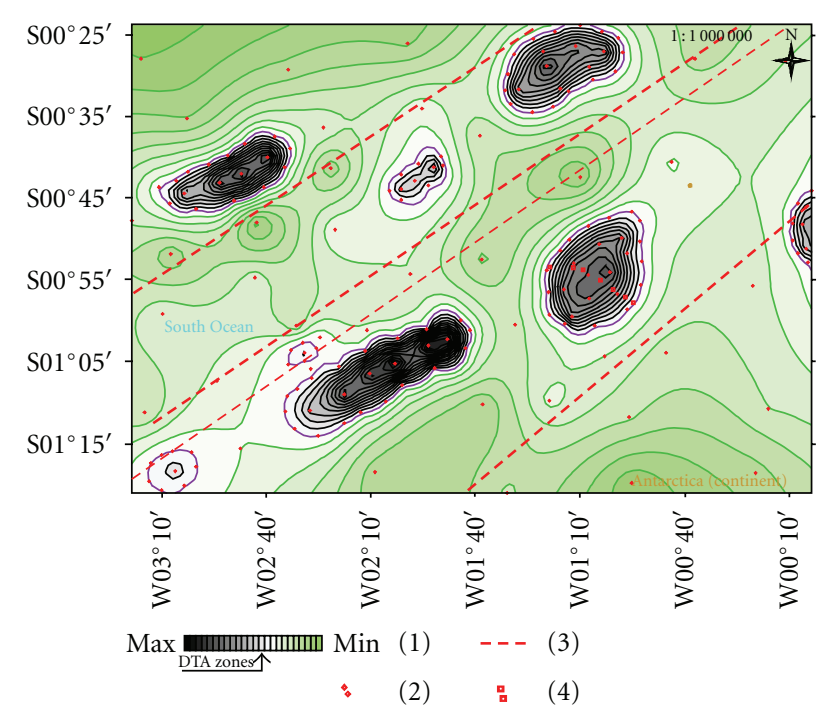

Figure 3: Map of anomalous zones of "oil deposit" type in the Antarctic region (relative coordinates, area of the "Academician Vernadsky"), allocated by the satellite data special processing and interpretation results. (1) The anomalous response intensity scale; (2) points of the anomalous response values; (3) predicted tectonic fractures; (4) points of "deposit" type anomalies registration by marine geoelectric methods FSPEF and VERS (2006).

The anomalous zones of "gas hydrates deposit" type were discovered and mapped only within two hydrocarbons deposits, and with the parameters of satellite data processing and interpretation, as in the Antarctic region. The anomalous zones of "gas hydrates deposit" and "gas deposit" types have been discovered and mapped with the satellite data processing in the southern part and anomalous zones of "gas deposit" and "oil deposit" types—in the northern part of the surveying area.

2.3. Pechora Sea Arctic Region of Russia. Six deposits are discovered on the Pechora Sea offshore: 4 oilfields (Prirazlomnoye, Varandey-More, Medynskoye-More 2, and Dolginskoye), North-Gulyaevskoe oil, gas, and gas-condensate field and Pomorskoye gas-condensate field. Oil pools are installed on the Medynskoye-More 2 field in the upper and lower Devonian and Silurian sediments. The area of Medynskaya-More 1 structure is located to south from Medynskoye-More 2 field (Figure 5).

The satellite data for this structure area were processed and interpreted. Large-scale anomalous zone of "hydrocarbon reservoir" type of high intensity was identified and mapped within the structure contours. The borehole, projected according to seismic and other geological and geophysical data, falls almost into the anomalous zone center. Nevertheless, the anomaly maximum is shifted slightly to the north-west of the project well point (Figure 6). Four small anomalous zones of low intensity and different scale were mapped to the east from anomalous zone over the Medynskaya-More 1 structure. The area of these anomalies location can be recommended for detailed study by other geophysical methods. Two anomalous zones of small area
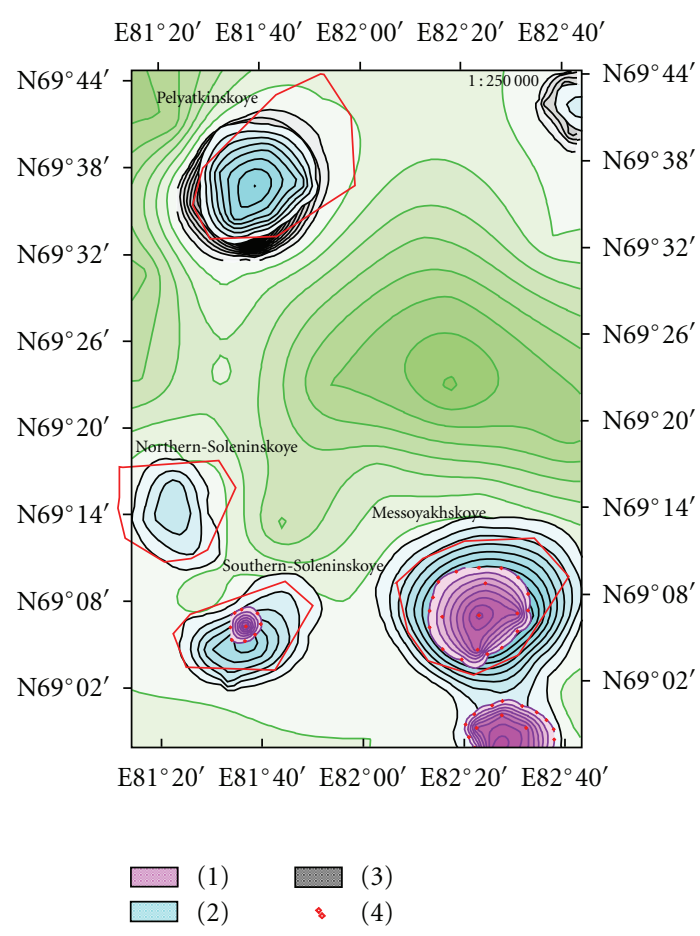

FIGURE 4: Map of hydrocarbon accumulations zones, produced on the satellite data processing results for the "Messoyakh" gas-hydrate deposit area (Western Siberia, Russia). (1) Zone of gas-hydrate deposits, (2) zone of gas deposits; (3) zone of oil deposits; (4) points of the anomalous responses registration from gas-hydrate deposits.

were identified also to the west of the Medynskaya-More 1 structure, and another-to the north. A large scaled anomalous zone of high intensity was fixed in the northeastern part of the satellite data processing and interpretation area.

This anomaly is even more large-scale than anomalous zone over the Medynskaya-More 1 structure. This area deserves high priority when the further exploration was carried out in this region. It is possible to suggest the fracture zones presence within the investigated site on the satellite data processing results. The possible fractures positions are also shown (Figure 6).

The received results indicate that the special technology of satellite data processing and interpretation may be applied for hydrocarbon accumulations prospecting and exploration in the Arctic and Antarctic regions of Earth.

2.4. Gulf of Mexico. This technology was used for the hydrocarbon deposits detection and possible risk determination of oil production at one of the Gulf of Mexico (GOM) local areas [11].

The intensive anomaly of "oil deposit" type has been isolated and mapped by the results of satellite data processing in the area of emergency drilling platform in the Gulf of Mexico (Figures 7 and 8).

The relative values of reservoir pressure were determined within most of the anomalies also. The dependence of the values of the anomalous response from the reservoir pressure 


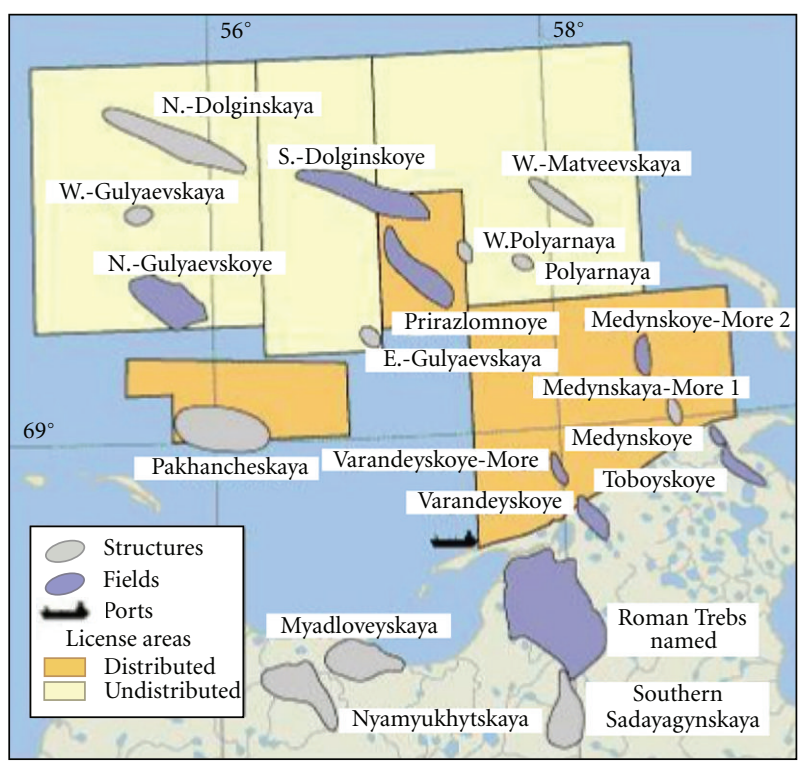

Figure 5: Sketch map of the structures and oilfields location in Pechora Sea, Arctic, Russia.

for gas has been installed by experimental measurements earlier. The scale of relative values of the pressure in the range from 0 to 6 has been formed by these data using. The relative value of reservoir pressure has been defined equal to 6 ; that is, the pressure in the wells is highest in comparison with those at other surveyed sites. In principle, this high values may be used to indicate the higher probability of commercial fluid inflow receiving. But too high expenses and risks that are related to gas hydrates production are reasons for terms transfer of these resources future mastering.

Satellite data from this region were also processed for the gas hydrates deposits detection and mapping (Figure 8 ). The same values of gas hydrates parameters, as in the Antarctic region and Messoyakh field, have been used satellite for data processing in this area. The results of satellite data processing showed that the "Deepwater Horizon," an emergency drilling platform had been situated in the center of "oil deposit" type anomaly with high-intensity values of reservoir pressure and in the anomalous zone of "gas-hydrate deposits" type with relative high intensity values of the response too. Such combination of anomalous areas promotes technological risks during drilling works in this place to a great extent. There are also another "oil deposit" type anomaly in northwestern part of district (Figure 7) with low layer pressure and anomaly of "gas-hydrate deposits" type with the higher intensity of anomalous response. Such combination of parameters specifies on relatively small potential of this deposit and promoted level of danger at his possible early development. These data also show the wide occurrences of the anomalous zones of "gas-hydrate deposits" type with relative high intensity values of the response.

On April 20, 2010 an explosion and fire racked the "Deepwater Horizon," a drilling platform operating in the Gulf of Mexico, in Mississippi Canyon. It may be assumed that the explosion of giant bubble of methane was one of the reasons of the "Deepwater Horizon" platform destruction.

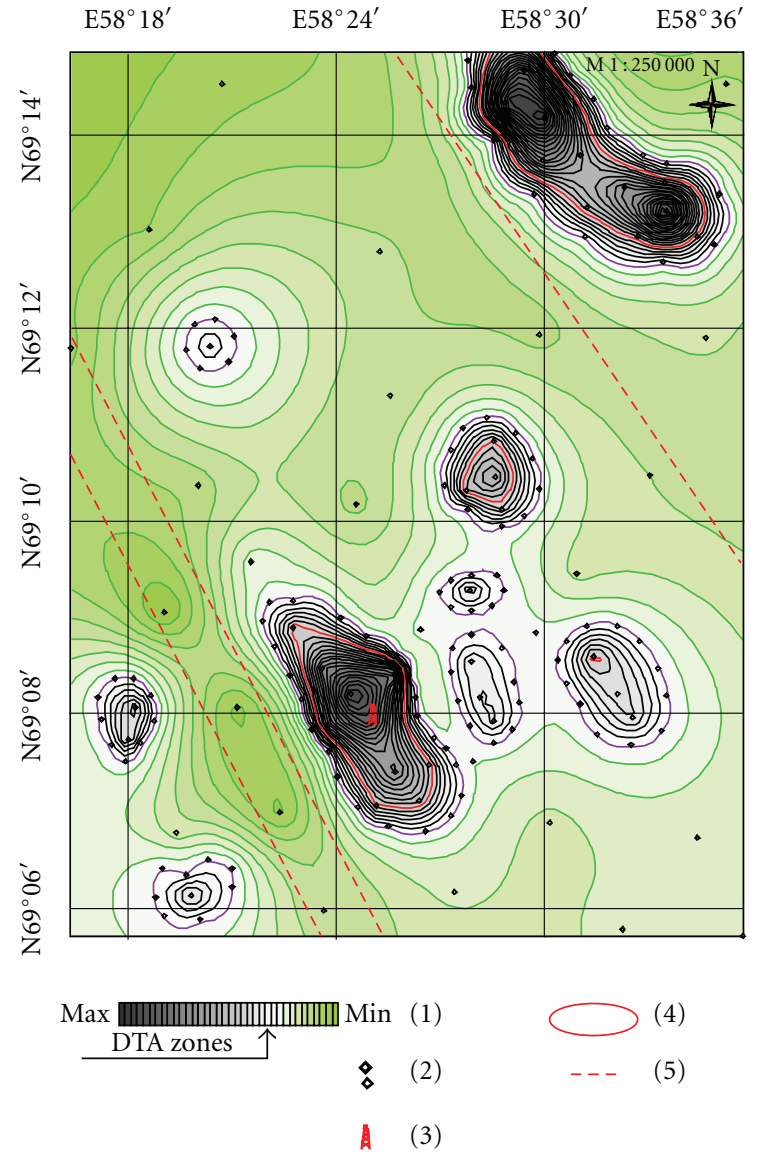

FIGURE 6: Sketch map of anomalous zones of "hydrocarbon deposit" type (DTA) in the "Medynskaya-More 1" structure region. (1) Scale of anomalous response intensity; (2) points of anomalous response determination;(3) location of projected well on the "Medynskaya-More 1" structure; (4) prognostic areas of oilsaturation maximum; (5) tectonic fracture zones.

The results of searching and mapping of hydrocarbon and gas hydrates accumulations in different regions show the necessity of this technology application especially on the early stages of researches when appears the possibility not only to detect the perspective on the different types of minerals areas but also to estimate possible risks during their future industrial development.

\section{Gas Hydrate Reservoir on the South Shetland Continental Margin (SSCM) Finding}

In some parts of the Antarctic Peninsula margin there are available all necessary thermobaric conditions for gas hydrates existence and their deposits formation that is proved by their distribution and concentration detection and mapping on South Shetland continental margin. The multichannel seismic data acquired on the South Shetland margin show that bottom simulating reflectors (BSR-s) are widespread at water depths ranging from 1000 to $4800 \mathrm{~m}$, implying large volumes of gas hydrates (Figure 9) [10-12].

According to sights of many researchers, this area represents "two distinct and superimposed tectonic regimes: 


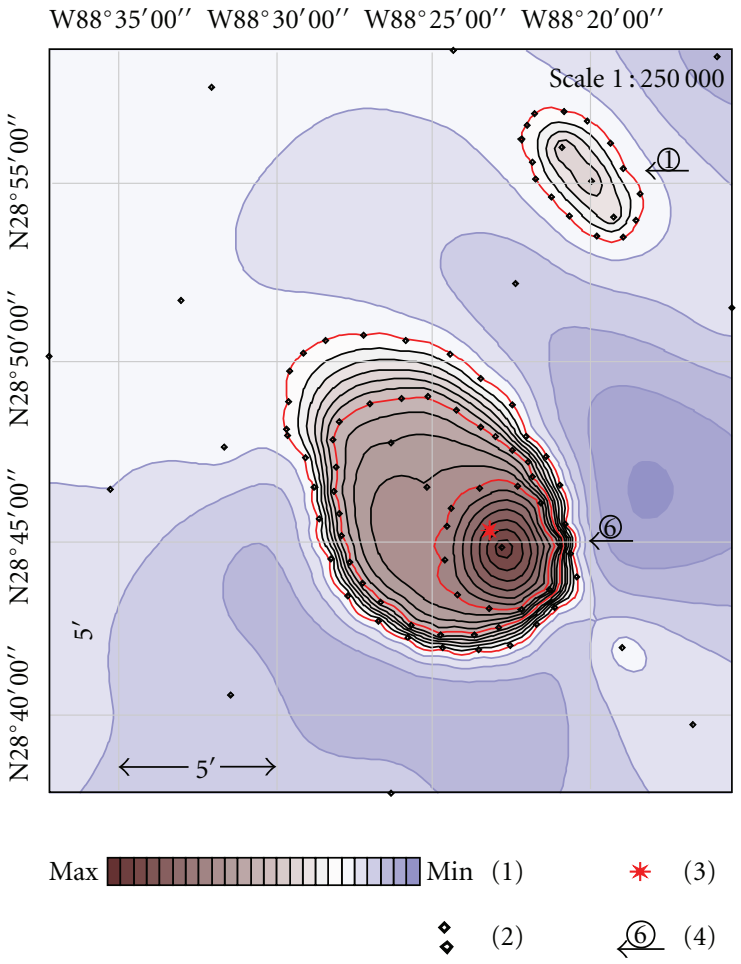

Figure 7: Map of the "oil deposit" type anomalies in the area of the "Deepwater Horizon" drilling platform in the Gulf of Mexico, based on the satellite data processing results. (1) Scale of the reservoir pressure relative values; (2) points of the anomalous response registration; (3) emergency platform location; (4) relative values of reservoir pressure in the anomalous zone.

an older regime is related to Mesozoic-Middle Cenozoic subduction-related tectonism of Gondwana margin; a younger one is associated with a mainly extensional tectonic phase, and related to the Oligocene development of the Western Scotia Sea" [11]. This part of continental margin is limited by two fracture zones, Shackleton (NE) and Hero (SW), the South-Shetland trench in a southeast and South Scotia Ridge in the East. The region of the triple junction between the Shackleton Fracture Zone, the South Shetland trench, and the South Scotia Ridge is an area where the BSRzones are the strongest [12-14].

Assumptions of researchers about other processes of bottom structures tectonic development of this region are quite proved. Geodynamic features of this region may be defined also as complex interaction of different age's continental and oceanic structures and are the result of active breaking which is connected with regional rifting processes $[13,15]$. It is possible to consider that numerous deep tectonic fractures assist to formation of natural gas migration ways towards the surface, creating the necessary conditions for stable BSR-zones appearance.

Satellite data over the BSR zones extension area, identified by seismic studies [10-12], have been processed and interpreted. The various processing parameters were analyzed for revealing and mapping the anomalous zone of "gas hydrates deposit" type within the surveying area (Figure 10).

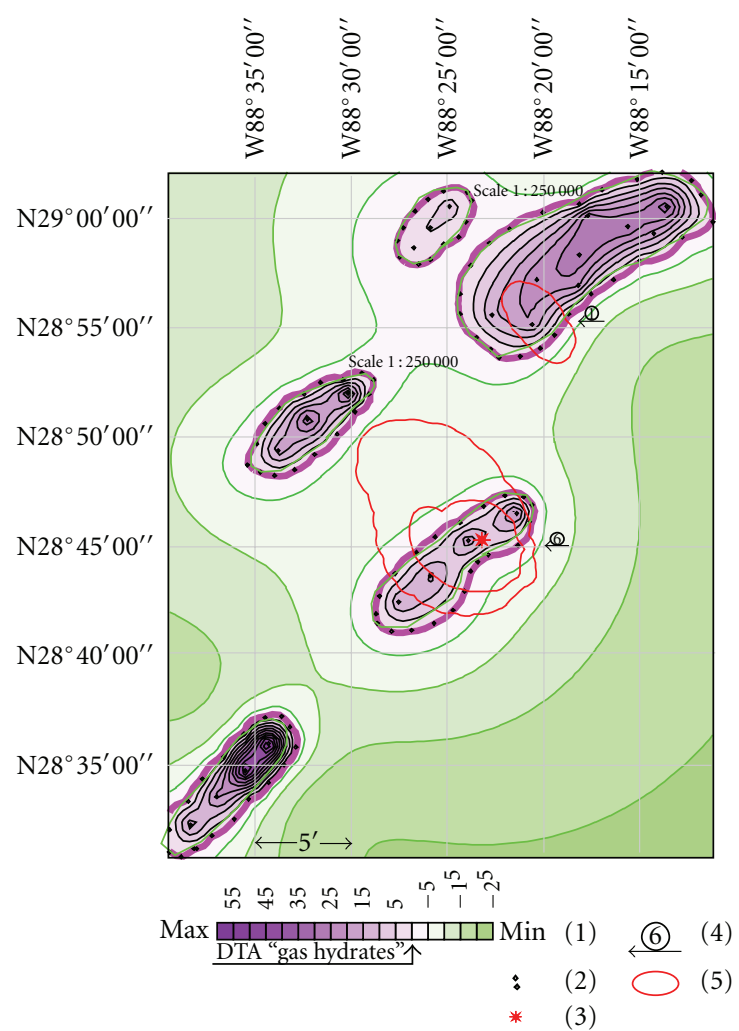

FIGURE 8: Map of anomalies of "gas-hydrate deposits" type in the area of the "Deepwater Horizon" drilling platform in the Gulf of Mexico. (1) Scale of intensity values of the anomalous response; (2) points of the anomalous response registration; (3) platform location; (4) relative values of the reservoir pressure in the anomalous zone; (5) contours of the anomalous zone of "oil pool" type, based on satellite data.

The contours of identified anomalous zones (Figure 10) are superimposed on the bottom topography map and the scheme of seismic profiles [12-14]. In general, the revealed and mapped anomalous zones of "gas hydrates deposit" type correlate satisfactory with BSR zones defined by seismic data.

The anomalous zones of "gas deposit" and "oil deposit" types were not detected within the surveyed sites. It was rather unexpected because the thickness of the free-gas zone was estimated on average to be about $50 \mathrm{~m}$, with local increases of as much as $400 \mathrm{~m}$ but variable average concentration $[13,14]$.

Possibly, free gas between the BSR and the Base of Gas Reflector accumulates in amounts that are insufficient for detection by this satellite method.

\section{Conclusions}

The results of the FSPEF-VERS technology obtained during the Ukrainian Antarctic expeditions have confirmed high efficiency of the separate methods of technology for different geological-geophysical problems decision.

(1) The "deposit" type anomaly was mapped by FSPEF survey in the Antarctic margin structure, and the 


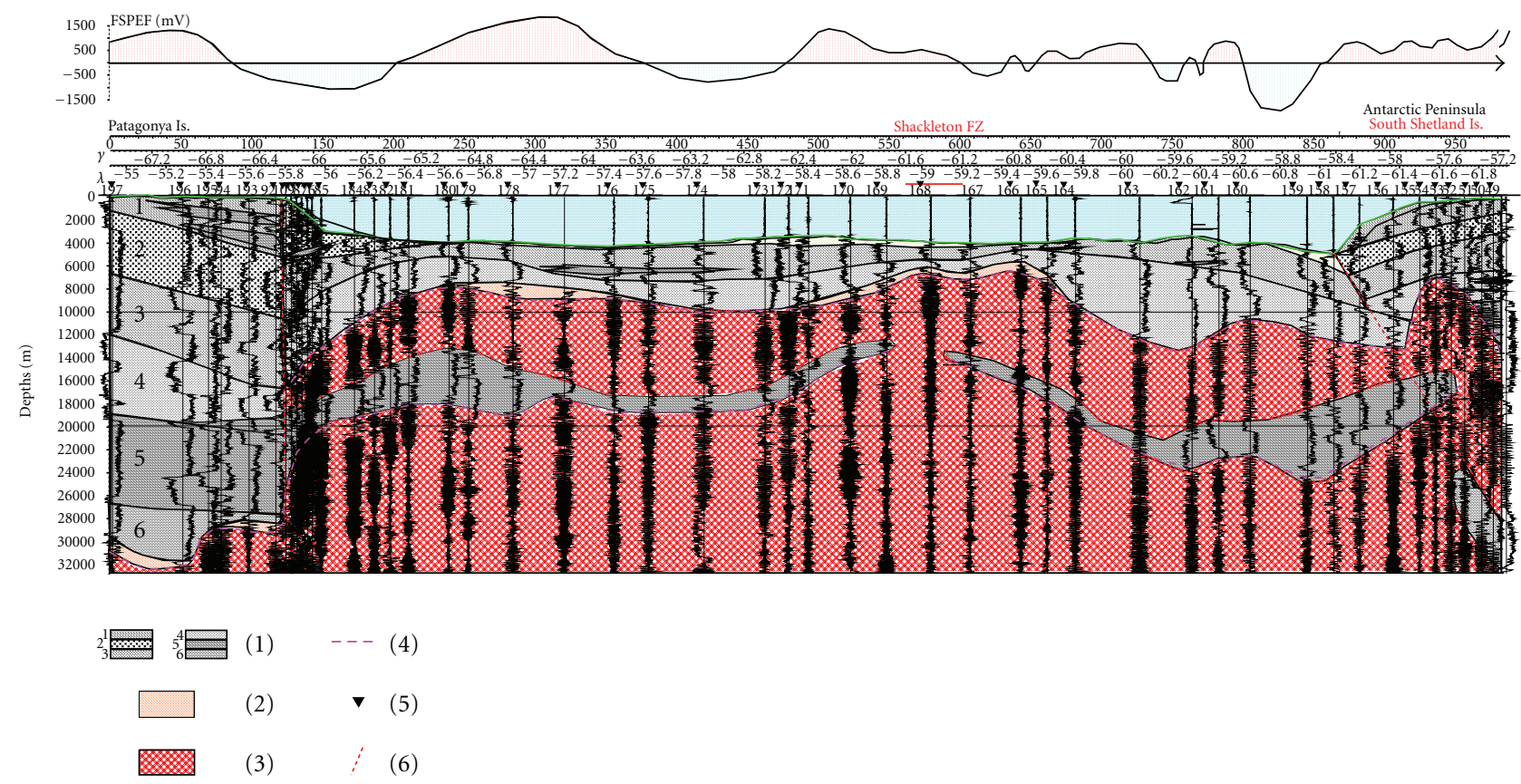

Figure 9: Interpreted geoelectrical cross-section of the crust and upper mantle along the profile through Drake Passage and the South Shetland Trench. Legend: (1) complex of volcanic and crystalline rocks; (2) rocks of crust-mantle transition layer; (3) upper mantle; (4) Moho boundary; (5) VERS points; (6) fracture zones.

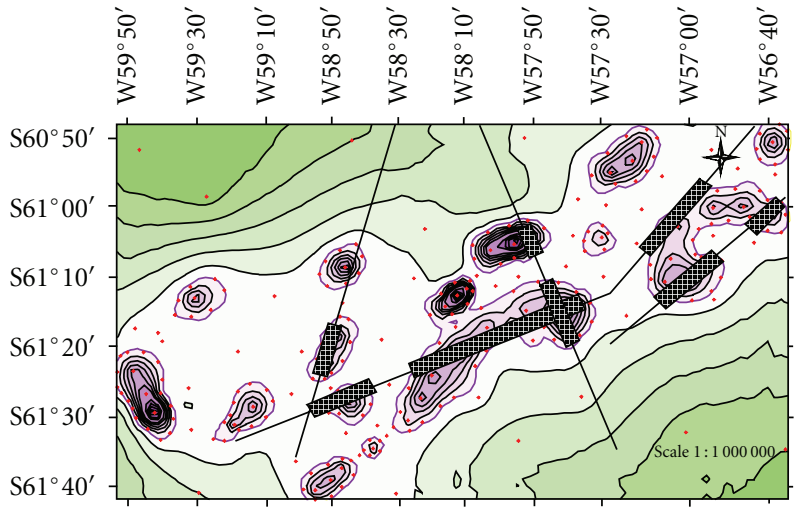

$\underset{\text { DTA "gas hydrates" }}{\text { Max }}$

(3)

Figure 10: Map of the anomalous zones of "gas hydrates deposits" type, produced by the special satellite data processing results (Antarctic Peninsula region). (1) Anomalous responses intensity scale; (2) points of the anomalous response values; (3) BSR zones defined by seismic data.

anomalous polarized layers of "hydrocarbon deposit" type were chosen by VERS sounding within this anomaly. This indicates the possibility of the FSPEFVERS technology using for hydrocarbon accumulation prospecting.

(2) Investigations have demonstrated high efficiency of the VERS method using for studying of the Earth's crust and upper mantle deep structure.

(3) First approbation of satellite special data processing and interpretation original technology was conducted on the known hydrocarbon fields and gas hydrates occurrences. This technology may be integrated also with the traditionally used methods of $\mathrm{HC}$ accumulations and gas hydrates prospecting as well as with nonclassical geophysical technologies. Our practical experiments testify that integration of satellite data processing and materials of FSPEFVERS methods enable improving their efficiency for different geological and geophysical problems solving. Obtained results confirm the high $\mathrm{HC}$ and gas hydrates potential of Antarctic Peninsula region.

\section{References}

[1] S. P. Levashov, N. A. Yakymchuk, I. N. Korchagin, and K. M. Taskynbaev, "Geoelectric investigations in Kenbye oilfield in Western Kazakhstan," in Proceedings of the 65th EAGE Conference and Technical Exhibition, vol. 2, p. 4, Stavanger, Norway, June 2003, Extended abstracts book, Poster Presentations, Absr. P154.

[2] V. P. Bokovoy, S. P. Levashov, N. A. Yakymchuk, I. N. Korchagin, and J. N. Yakymchuk, "Mudslide area and moistening zones mapping with geophysical methods on the slope of the Dniper river in Kyiv," in Proceedings of the 65th EAGE Conference and Technical Exhibition, vol. 2, p. 4, Stavanger, Norway, June 2003, Extended abstracts book, Poster presentations, Absr. P208.

[3] S. P. Levashov, N. A. Yakymchuk, I. N. Korchagin et al., "Electric- resonance sounding method and its application 
for the ecological, geological-geophysical and engineeringgeological investigations," in Proceedings of the 66th EAGE Conference \& Exhibition, 2004, Extended Abstracts P035.

[4] V. Bakhmutov, V. Solovyov, I. Korchagin et al., "Drake passage: crustal structure, tectonic evolution and new prognosis for local HC accumulations along the Antarctic Peninsula margin," Geophysical journal, vol. 32, no. 4, pp. 12-15, 2010.

[5] N. A. Yakymchuk, S. P. Levashov, and I. N. Korchagin, "Express-technology for direct searching and prospecting of hydrocarbon accumulation by geoelectric methods," in Proceedings of the International Petroleum Technology Conference, p. 11, Kuala Lumpur, Malaysia, December 2008, Paper IPTC12116-PP. CD-ROM.

[6] S. P. Levashov, N. A. Yakymchuk, and I. N. Korchagin, "Drake passage and bransfield Strait-new geophysical data and modelling of the crustal structure," in Proceedings of Antarctica: A Keystone in a Changing World-Online Proceedings for the 10th International Symposium on Antarctic Earth Sciences (ISAES '07), A. K. Cooper, C. R. Raymond et al., Eds., 2007, USGS Open-File Report 2007-1047.

[7] Direct Hydrocarbon Detection, http://www.wavetechnologygroup.com/.

[8] N. Kovalev, V. Goh, S Soldatova, and I. Lyamtseva, "Using of geogologographical complex "Search" for hydrocarbons detecting," Geoinformatika, no. 3, pp. 83-87, 2009.

[9] V. V. Rostovtsev, V. N. Rostovtsev, and B. B. Laynveler, "To great oil deposits of Russia," Geomatics, no. 1, pp. 60-63, 2011 (Russian), http://www.geomatica.ru/eng/.

[10] Y. F. Makogon, F. A. Trebin, A. A. Trofimuk, and V. P. Cherskii, "Detection of a pool of natural gas in a solid hydrate state," Doklady Akademii Nauk SSSR, vol. 196, no. 1, pp. 197-200, 1971.

[11] K. A. Kvenvolden and T. D. Lorenson, "The global occurrence of natural gas hydrate," in Natural Gas Hydrates: Occurrence, Distribution, and Detection, C. K. Paull and W. P. Dillon, Eds., vol. 124 of Geophysical Monograph, pp. 3-18, American Geophysical Union, Washington, DC, USA, 2001.

[12] Y. K. Jin, M. W. Lee, Y. Kim, S. H. Nam, and K. J. Kim, "Gas hydrate volume estimations on the South Shetland continental margin, Antarctic Peninsula," Antarctic Science, vol. 15, no. 2, pp. 271-282, 2003.

[13] E. Lodolo, A. Camerlenghi, G. Madrussani, U. Tinivella, and G. Rossi, "Assessment of gas hydrate and free gas distribution on the South Shetland margin (Antarctica) based on multichannel seismic reflection data," Geophysical Journal International, vol. 148, no. 1, pp. 103-119, 2002.

[14] U. Tinivella, F. Accaino, and A. Camerlenghi, "Gas hydrate and free gas distribution from inversion of seismic data on the South Shetland margin (Antarctica)," Marine Geophysical Researches, vol. 23, no. 2, pp. 109-123, 2002.

[15] H. W. Schenke and G. B. Udintsev, "The central scotia seafloor-is it an paleo-oceanic plate, an young rifted plate or an paleo-land Scotia?" Ukrainian Antarctic Journal, no. 8, pp. 36$45,2009$. 

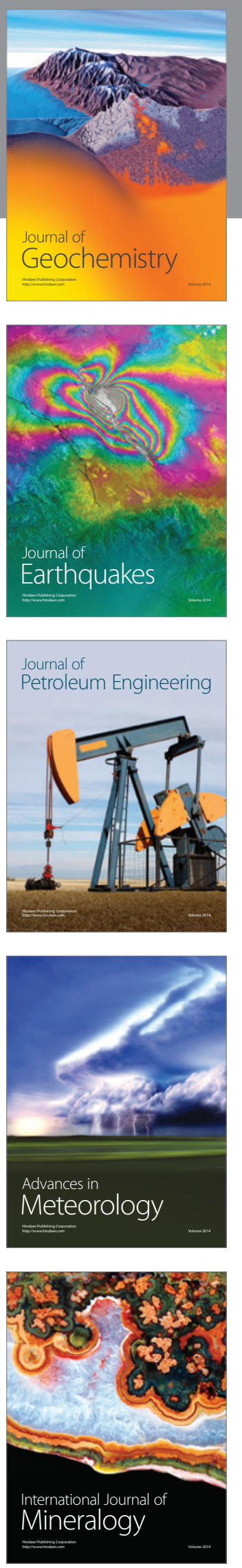
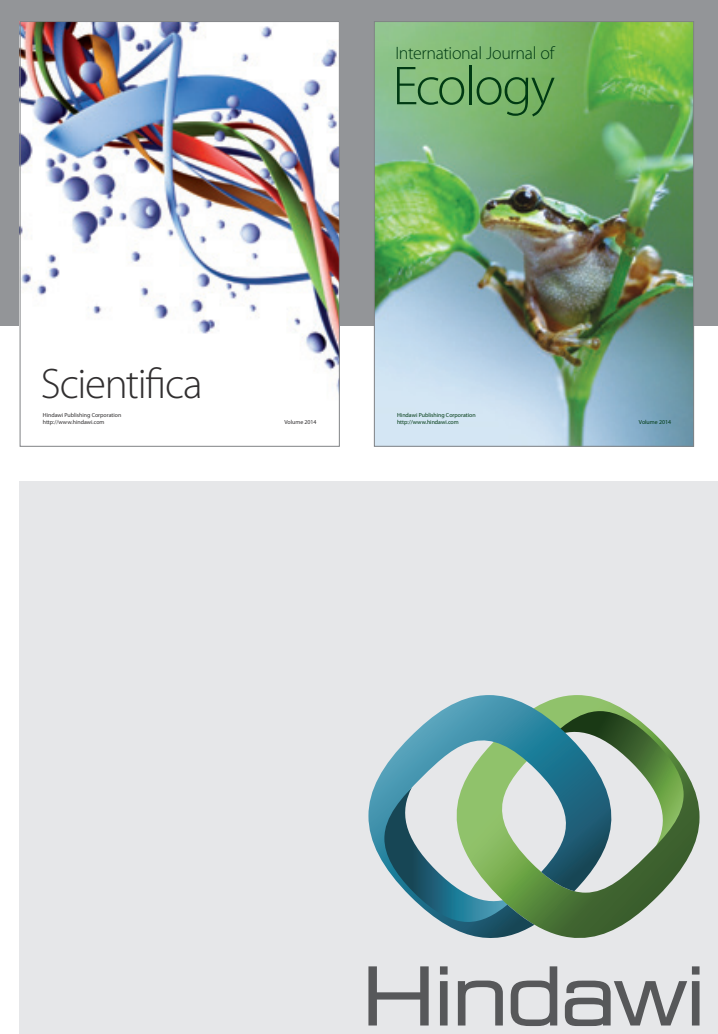

Submit your manuscripts at http://www.hindawi.com
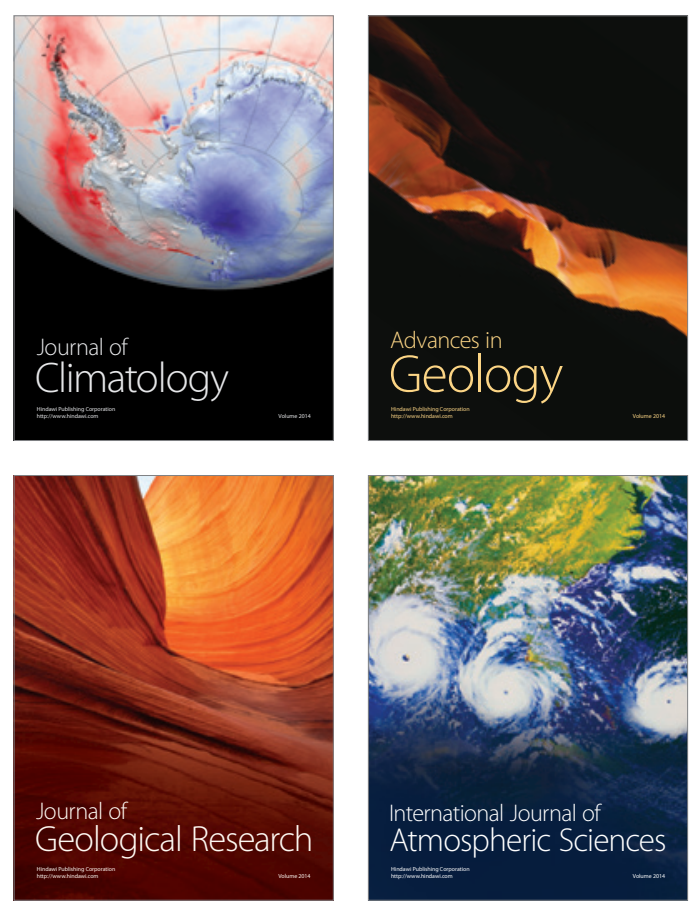
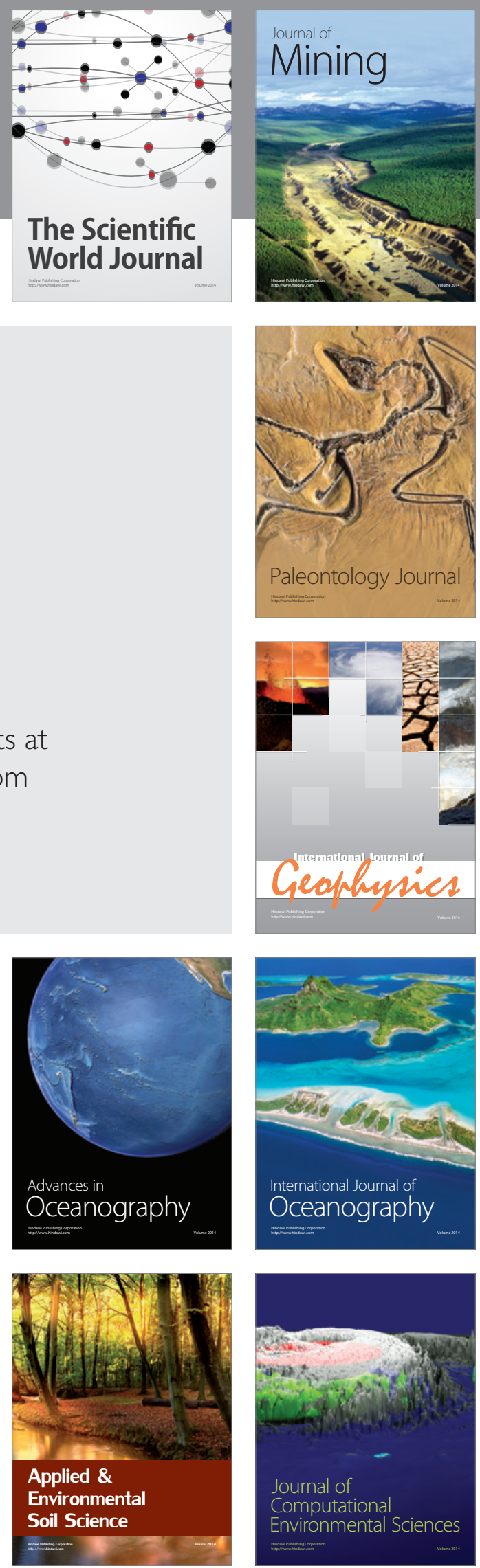